\title{
EUGENIO FUENTES Y LA (RE)CREACIÓN DEL GÉNERO POLICIACO
}

\author{
JAVIER SÁNCHEZ ZAPATERO \\ Universidad de Salamanca \\ zapa@usal.es
}

\section{RESUMEN}

El artículo analiza las obras que integran la serie de novelas negras protagonizadas por el detective Ricardo Cupido, escritas por Eugenio Fuentes durante las décadas de 1990 y 2000. Además de centrarse en diversos aspectos narratológicos, el artículo reflexiona sobre el modo en que las novelas respetan y a la vez subvierten las características básicas del género.

Palabras Clave: Eugenio Fuentes, Novela Negra, Literatura Española Contemporánea

\section{Abstract}

The paper analyzes the crime novels by Ricardo Cupido, featuring the private detective Ricado Cupido (1990s-2000s). The paper studies some narratological aspects and reflects how these novels respect and subvert the basic features of crime stories.

KeY WORDs: Eugenio Fuentes, Crime Story, Comtemporary Spanish Literature 


\section{El CONTEXTO: LA NOVEla NEGRA ESPAÑOLA DEL SIGLO XXI}

Nacido en la localidad cacereña de Montehermoso en 1958, Eugenio Fuentes ha logrado convertirse en uno de los más destacados representantes de la novela negra ${ }^{1}$ española de la actualidad gracias a la serie narrativa protagonizada por el detective Ricardo Cupido. Así lo atestiguan la proyección internacional de su obra, que ha sido traducida ya a doce idiomas; la consecución de varios galardones, algunos de ellos especializados, como el que otorgó la Asociación para la Difusión de la Novela Negra «Brigada 21» a su novela Cuerpo a cuerpo en 2008²; o las palabras de los críticos Santos Sanz Villanueva (2007) -para quien el autor es «uno de los más notables e interesantes narradores (...), uno de los más serios y solventes entre la nómina inacabable de quienes hacen novela negra»- o Ricardo Senabre (2003) -quien ha afirmado que Fuentes «utiliza con destreza los resortes del género»-.

La «serie Cupido» está integrada por las novelas El nacimiento de Cupido (1994), El interior del bosque (1999), La sangre de los ángeles (2001), Las manos del pianista (2003), Cuerpo a cuerpo (2007) y Contrarreloj (2009)3. Grosso modo, las fechas de publicación de las obras coinciden con la época de eclosión del género negro en la literatura española. Desde el comienzo del siglo Xxi, diversas circunstancias literarias y culturales han contribuido al desarrollo de esta modalidad narrativa, convirtiéndola en una de las de mayor presencia editorial en la actualidad. El asentamiento de festivales como la Semana Negra de Gijón o BCNegra; la creación de una enorme red de páginas webs, foros y blogs especializados; el progresivo aumento del corpus académico e investigador dedicado al tema o el empeño de prácticamente todas las editoriales en incluir en su catálogo obras adscritas al género han sido algunos de los factores que han provocado el auge de la novela negra, al que también han contribuido fenómenos editoriales como el protagonizado por la trilogía de Stieg Larsson.

De este modo, el nombre de Eugenio Fuentes ha de sumarse al de Lorenzo Silva o Alicia Giménez Bartlett, quienes también comenzaron sus sagas detectivescas -protagonizadas, respectivamente, por el agente de la Guardia Civil Rubén Bevilacqua y la inspectora Petra Delicado- a mediados de la década de 1990. Estos tres autores pueden considerarse abanderados de la nueva generación de escritores de novela negra de la literatura española, cuya nómina se ha ido ampliando en los últimos años gracias a la aparición de Domingo Villar, Luis Gutiérrez, Carlos Zanón, Willy Uribe o David Torres -o al cultivo del género de escritores como José María Guel-

\footnotetext{
1 Aunque en numerosas ocasiones «novela negra» se utiliza como sinónimo de «novela policiaca», resulta más apropiado referirse a la primera como resultado de la reconversión de la segunda «en una literatura de alcance social que desdeña el universo burgués y el simple divertimento mental que, protagonizada por un nuevo tipo de detective privado -el hard-boiled [traducido literalmente como 'duro y en ebullición' o, de forma menos rigurosa como 'duro de pelar'], casi tan violento, cínico y marginado como un delincuente- aborda con honestidad, rigor, y realismo la cotidiana realidad criminal» (Alonso y Santamaría: 22-23).

2 Las otras novelas de la «serie Cupido» premiadas han sido El nacimiento de Cupido, que recibió en 1993 el Premio Internacional de Novela Ciudad de San Fernando «Luis Berenguer» y El interior del bosque, galardonada con el IX Premio Alba de la Prensa Canaria en 2001.

3 Además, Fuentes es también autor de las novelas Las batallas de Breda (1990) -en la que, como ya se desgranará, aparece el personaje de Cupido-, Tantas mentiras (1997) y Venas de nieve (2005); de los ensayos La mitad de Occidente (2003) y Tierra de fuentes (2010), y de la compilación de relatos Vías muertas (1997).
} 
benzu, con una destacada obra literaria a sus espaldas antes de publicar, en 2001, la primera de las entregas de su saga protagonizada por la jueza Mariana de Marco-.

A pesar de las evidentes diferencias temáticas y formales de la obra de estos autores, y de los riesgos que siempre conlleva proyectar una visión unitaria sobre una serie de escritores heterogéneos vinculados por su adscripción a unas características tradicionalmente identificadas como propias de un subgénero narrativo y por su coincidencia contextual, no parece muy descabellado señalar que una de las señas de identidad de la novela negra española durante la última década es su progresivo alejamiento de los modelos instaurados en la época de la Transición gracias a la obra de Manuel Vázquez Montalbán, Juan Madrid, Francisco González Ledesma, Andreu Martín o Jorge Martínez Reverte. Tal y como ha señalado Colmeiro (1994: 213), en la obra de estos autores es posible detectar un nexo común basado «en el relejo de los problemas más acuciantes de la sociedad contemporánea» y, de forma más concreta, «en la crítica irónica e inconformista de la sociedad española contemporánea». De algún modo, es posible interpretar las novelas de quienes impulsaron el género negro en la literatura española durante los últimos años de la década de 1970 y los primeros de la de $1980^{4}$ como una crónica de los acontecimientos vividos durante los convulsos años de reforma política en España. En ese sentido, resulta sintomático que Juan Madrid (1986: 25) señalase que sus novelas se dedicaban a «viviseccionar el momento actual» o que Manuel Vázquez Montalbán (apud Tyras 2003: 103) definiese las diferentes entregas de la «serie Carvalho» como «novelas realistas, crónica de la que va a ser la vida española de transición desde la decadencia del franquismo».

\section{El ESPACIO: BREDA}

Carentes de esta concepción social y crítica de la literatura -presente también en autores clásicos del género como Raymond Chandler o Dashiell Hammett ${ }^{5}$-, las obras de Eugenio Fuentes pueden ser adscritas a la novela negra por su utilización de una serie de recursos formales, temáticos y pragmáticos basados, simplemente, en la presencia de un acto delictivo - generalmente, un crimen-, en el mantenimiento de una intriga que genera la interacción lúdica del lector y en la aparición de un personaje que lleva a cabo la investigación. Estos elementos son, según Tzvetan Todorov

4 Debido a diversas circunstancias sociales, históricas, políticas y culturales -basadas, grosso modo, en la ausencia de una clase burguesa dominante que impulsase en el siglo XIX la creación de una tradición autóctona de literatura policiaca; en el desprecio con el que las elites culturales juzgaron siempre a las narrativas populares; y en la imposibilidad de que un tipo de novela basada en el desorden social y la criminalidad fructificase durante la dictadura franquista-, la novela negra no pudo desarrollarse en España hasta mediados de la década de 1970. Para profundizar en esta anómala evolución, pueden consultarse los estudios de Colmeiro (1994), Resina (1997), Valles Calatrava (1991) o Vázquez de Parga (1993).

5 Si los escritores norteamericanos describieron las miserias de una sociedad corrupta en crisis permanente tras los fenómenos del primer cuarto de siglo, los autores españoles de la Transición hicieron una crónica de los acontecimientos acaecidos tras la muerte del dictador caracterizada por su concreción histórica. Del mismo que los personajes hard-boiled simbolizan el desencanto de una generación ante la crisis de valores producida por el derrumbe de los sistemas positivistas, los de los escritores nacionales muestran la frustración ante las transformaciones sociales, políticas y económicas producidas después de 1975 y ante la constatación del fracaso de todo el idealismo utópico que rodeó los primeros meses de reforma democrática. 
(1974: 63-77), suficientes para conformar el esquema argumental de la novela negra, que se basa en una estructura dual de la que forman parte la historia del crimen -lo ausente, sólo conocido por la víctima y el criminal- y la historia de la investigación -lo presente, sólo conocido por el investigador y los lectores-. La labor del investigador, por tanto, será, a través de sus pesquisas, hacer que lo ausente pase al plano del presente, función que en las novelas de Fuentes lleva a cabo el detective privado Ricardo Cupido.

El personaje, además de en la serie negra, aparece también en Las batallas de Breda (1990), la obra con la que Fuentes debutó en el panorama literario -y por la que fue galardonado con el Premio Cáceres de Novela Corta-, y en el relato «Perseo en Breda», finalista de los Premios de Relato de la Fundación de Max Aub de 1988. Mientras que el resto de novelas muestran la actividad de Cupido como detective privado, estos dos títulos presentan al personaje en su juventud.

Las batallas de Breda, es un relato iniciático coral que muestra como un grupo de adolescentes va entrando en la edad adulta a través de su progresivo conocimiento del sexo, el amor, la muerte, la responsabilidad, el desengaño, etc. Cupido, conocido por sus amigos en aquellos tiempos como «Kao», es uno más de los que conforman el fresco de personajes que protagonizan -y narran polifónicamente- la historia. En la novela apenas se dan un par de datos sobre él: se le describe como «el más arrogante y atractivo» (Fuentes, 1990: 122) del grupo de amigos, se relatan sus primeros escarceos amorosos y se da cuenta de su pertenencia a un linaje de contrabandistas ${ }^{6}$. La actividad delictiva de su familia es el tema central del relato «Perseo en Breda», en el que Cupido, convertido ya en protagonista y único narrador, relata el tráfico ilegal de productos por la frontera hispano-lusa.

Tal y como puede detectarse por el título de las dos narraciones, el espacio en el que se desarrollan los acontecimientos es la ciudad de Breda, un escenario ficticio que, sin embargo, no resulta difícil de identificar con el del norte de Extremadura, lugar de nacimiento de Fuentes. El propio escritor ha reflexionado sobre este escenario, afirmando que en su gestación pesaron tanto la influencia de autores como Juan Benet, Juan Carlos Onetti, Gabriel García Márquez o William Faulkner, creadores también de sus propios territorios novelescos, como la necesidad de dar una imagen de Extremadura alejada de «aquella otra de exclusivo color amarillo que los escritores regionalistas del primer tercio del siglo xx describieron: una región parada, seca, pobre, doliente e inmovilizada en una especie de eterno verano telúrico» (Fuentes 2005: 74)7 . Frente a la visión de la zona que dieron autores como Antonio Reyes Huertas, Luis Chamizo o Felipe Trigo, Fuentes crea un espacio, a medio camino entre lo legendario, lo ficticio y lo referencial, poblado de bosques, ríos, pantanos y montes. En ese escenario de evidente riqueza de flora y fauna, junto a una serie de

\footnotetext{
6 «Su abuelo había sido el primero en asustar a los montesinos con el fragor de las bielas y pistones del primer camión que recorrió nuestras calles empedradas, camión luego requisado en la guerra al servicio de otros fines. Y su padre, camionero y contrabandista de perfume, café y tabaco, había heredado el oficio. Algunas veces lo llevaba con él para que aprendiera el trabajo y la mecánica, según decía, aunque la primera intención era evitar con la imagen familiar la sospecha de los Civiles» (Fuentes, 1990: 54).

7 La actitud revisionista y desmitificadora sobre la tópica imagen que se ha dado de Extremadura es el tema central del volumen de ensayos del autor Tierra de fuentes.
} 
lugares como la reserva natural del Patérnoster, el Volcán, el río Lebrón o la Fuente de Chica Cabrera, se sitúa Breda, una pequeña ciudad de provincias situada «en una tranquila equidistancia la vieja villa anclada en sus costumbres y ascendencia rural y la mediana urbe de servicios» (Fuentes, 2008: 33).

Breda ha continuado apareciendo en la serie policiaca protagonizada por Ricardo Cupido, confirmando así la tendencia «descentralizadora» con la que se está superando en los últimos años el innegable protagonismo espacial de Barcelona y, en menor medida, de Madrid en la novela negra española de las décadas de 1970 y 1980. La condición emblemática de los centros políticos, económicos, culturales y empresariales del país, así como la influencia de las sagas novelescas de autores pioneros del género como Manuel Vázquez Montalbán, Juan Madrid o Francisco González Ledesma, motivó la constante utilización de los principales focos geográficos de poder como lugares de la acción argumental. El recorrido por lugares de la península ibérica que acostumbran a hacer los personajes de Lorenzo Silva, o la ubicación de las tramas de las novelas de Domingo Villar o Suso de Toro en Galicia -o las de José Javier Abasolo y Willy Uribe en el País Vasco, o las de José Luis Serrano en Andalucía- han acabado con esta tendencia, también contrarrestada por la aparición de un escenario identificado con una ciudad de provincias como Breda.

El uso reiterativo del escenario en las novelas de Fuentes está intrínsecamente relacionado con su condición serial, puesto que, como han apuntado Balló y Pérez (2005: 37), «a menudo la literatura de sagas detectivescas se ha sustentado en la creación de un espacio estable» capaz de proporcionar a los lectores un doble placer basado en el reconocimiento y en la gratificación basada en el deseo de regeneración de, precisamente, lo descubierto en las entregas anteriores. La estabilidad de ese espacio se complementa con la de los personajes secundarios que acompañan a los protagonistas, bien en su ámbito doméstico, bien en su ámbito profesional, que muchas veces presentan unas funciones delimitadas y reconocibles en la estructura de la narración, «de manera que el lector ya sabe con antelación la reacción que va a tener el personaje o lo que va a hacer» (Casadesús, 2010: 90). Su presencia constante en las obras permite también que, junto a las tramas clausuradas de cada de una de las entregas, haya otras abiertas que van dando continuidad a la serie de novelas. Así, junto a los argumentos de misterio de cada una de las obras, se va profundizando en la vinculación del protagonista con otros personajes como «el Alkalino»-amigo, confidente y consejero- o el teniente Gallardo, con quien, después de superar los habituales recelos con los que los miembros de los Cuerpos de Seguridad del Estado ven a los investigadores privados, logra trabar una relación basada en el afecto, la admiración y la colaboración en la resolución de algunos casos delictivos.

\section{El PERSONAJE: RicARdo CUPido}

Pero, sin duda, la trama que estructura toda la serie y que permite que todas sus novelas adquieran una continuidad evolutiva capaz de trascender el carácter finito de cada uno de los casos detectivescos que presentan es la que hace referencia a la incógnita que supone el propio personaje de Ricardo Cupido. Prácticamente nada se sabe del 
investigador, más allá de los datos sobre su adolescencia que se dan en las dos obras que anteceden a la serie negra; de la experiencia carcelaria con la que terminan sus escarceos con el contrabando -relatada en los primeros capítulos de El nacimiento de Cupido, y también en Contrarreloj, en la que, además de describir el delito de tráfico ilegal de tabaco rubio por el que acabó entre rejas, se evocan muy someramente algunas de sus rutinas en la prisión-; de algunos datos familiares -la muerte, siendo niño, de su hermano; los cuidados a los que ha de someter a su anciana, y enferma, madre-; y de su afición al ciclismo ${ }^{8}$. Montar en bicicleta es para el personaje una forma de desplazarse, de mantenerse en forma y, sobre todo, de evadirse de la rutina y aclarar sus ideas cuando ha de enfrentarse a la resolución de un caso, pues, como se afirma en Cuerpo a cuerpo, «pedaleando despacio, podía abstraerse del esfuerzo físico y recapitular lo que había averiguado hasta ese momento» (2007: 197).

El papel del ciclismo en la «serie Cupido» adquiere gran trascendencia, pues, además de convertirse en el marco ambiental de una de sus entregas ${ }^{9}$, condiciona el discurso narrativo, ya que la descripción detallada del esfuerzo en la carretera del personaje permite dilatar el ritmo de la acción, explicitar las reflexiones sobre el caso del investigador y, en definitiva, contribuir al mantenimiento de la intriga. Lejos de ser baladí, la presencia de la afición deportiva del personaje sirve también para vincular la narrativa de Fuentes con el canon genérico al que se adscribe. No en vano, desde los primigenios relatos policiacos de los que proceden, es habitual en las novelas negras presentar a los investigadores envueltos en un halo de misterio, de forma que las únicas informaciones que de ellos conocen los lectores son las relacionadas con su capacidad deductiva y su forma de afrontar y solucionar los casos. La ausencia de informaciones sobre la vida privada de los personajes fundacionales del género es contrarrestada con la introducción en su creación y descripción de una serie de excentricidades y manías -como la afición al violín de Sherlock Holmes o el gusto por la cría de orquídeas de Nero Wolfe- que

\footnotetext{
8 «Siempre le había gustado el ciclismo y nunca había dejado de practicarlo (...). Era un deporte lleno de atractivos, que enseguida convertía en adeptos a quienes lo practicaban. Por una parte, no era aburrido como el jogging, exigía menos intensidad en terrenos llanos y tenía un recorrido espacial más largo que permitía mayor movilidad, gozar de más variedad de paisajes. Y no había que estar siempre moviendo las piernas. En toda ruta, siempre hay una bajada, un descanso. Por otra parte, no requería el largo y tedioso aprendizaje de una técnica hasta llegar al momento de disfrutarlo, como le había ocurrido con el tenis. Montar en bicicleta le parecía algo tan sencillo como caminar. Además, no se necesitaba a alguien más para practicarlo: era un placer que se podía gozar solo o en compañía. (...) Al no ser un deporte de enfrentamiento directo con el adversario, no era necesaria la aplicación de todo el brío y la potencia que el tú a tú del fútbol, del baloncesto o del tenis exigían (Fuentes, 2008: 179).

9 Si en las primeras entregas de la serie la afición al deporte era un mero elemento tangencial que permitía al personaje reflexionar y ordenar todas las piezas de la investigación, en Contrarreloj el ciclismo y su práctica profesional se convierten en el contexto en el que transcurre la historia. La novela, de hecho, se divide en tantos capítulos -veintiuno- como etapas tiene el ficticio Tour de Francia al que Ricardo Cupido ha acudido como espectador. Instalado en un hotel de los Pirineos junto a su amigo «el Alkalino», el detective planea pasar sus vacaciones estivales practicando ciclismo de alta montaña -en concreto, intentando ascender a la siempre desafiante cumbre del Tourmalet, una de las cimas míticas del Tour- y, de paso, presenciando en directo una de las etapas de la ronda francesa. Con el descubrimiento del cadáver de Tobias Gros, favorito y dominador de la prueba en las últimas ediciones, los días de asueto pronto se transformarán en jornadas de trabajo para el detective, contratado para aclarar los detalles de la muerte del corredor. El planteamiento de la obra recuerda así al de buena parte de las novelas policiacas clásicas de Agatha Christie, en las que los detectives parecían llevar el crimen allá donde iban, y, al mismo tiempo, el de cierta tradición de género negro vinculada al deporte -fundamentalmente, al boxeo y a su submundo de apuestas y combates ilegales-.
} 
quedarán configuradas como «marcas de género» y que, como tal, aparecerán en muchos de los protagonistas de la novela negra del siglo xx. Como si de un icono se tratase, este elemento simbólico es capaz de resumir y representar sus principales señas de identidad. En este de grupo de comportamientos ha de encuadrarse la afición de Cupido por el ciclismo, símbolo de la soledad con la que el detective se enfrenta a los casos y, en general, a la vida, tal y como se evidencia en los siguientes pasajes de una de las novelas de la serie: «Se había ido volviendo aún vez más hermético. A todos ocultaba sus decepciones, su soledad, sus temores (...). Los guardaba allí donde no estuvieran al alcance» (Fuentes, 2007: 74).

Raymond Chandler puso de manifiesto en su ensayo El simple arte de mata cómo los personajes detectivescos habían de interesar al lector fundamentalmente por su vinculación con la trama de intriga a la que tenían que enfrentarse y no por sus anécdotas personales ${ }^{10}$, máxima a la que Fuente se somete al presentar a su personaje entre el misterio y la ausencia de informaciones sobre su vida. De hecho, aunque parezca paradójico, Cupido no es, en sentido estricto, el protagonista de ninguna de las novelas en las que aparece -excepto de El nacimiento de Cupido, de la que es, además, narrador-. Según Senabre (2003), el personaje «queda en penumbra, como un contemplador lejano», de tal forma que «la faceta de relato de misterio con que se presenta la novela es (...) simple fondo bosquejado para inscribir en él algunas vidas». La función del personaje se limita a ser la del ojo crítico e investigador que intenta descubrir qué ha ocurrido en los casos delictivos que le encargan resolver.

El interior del bosque, La sangre de los ángeles, Las manos del pianista, Cuerpo a cuerpo y Contrarreloj son novelas corales en las que el detective ha de introducirse en diversos ambientes para investigar y en las que, en consecuencia, el protagonismo va a recaer sobre la galería de personajes que ante él van a desfilar, miembros de herméticos microcosmos que van a ver con recelo las pesquisas de un extraño como Cupido. Así, por ejemplo, en La sangre de los ángeles el detective habrá de investigar a los miembros del claustro de un colegio para resolver el asesinato de un profesor, en Cuerpo a cuerpo tendrá que inmiscuirse en el ambiente castrense para descubrir las circunstancias en que se produjo la muerte de un militar y en Contrarreloj se verá obligado a introducirse en el mundillo ciclista para resolver una serie de extraños y dramáticos sucesos que afectan a la caravana del Tour de Francia.

La condición profesional de Ricardo Cupido dota de cierto carácter anómalo y excepcional a la obra de Eugenio Fuentes dentro de la novela negra española contemporánea, en la que los detectives han perdido su tradicional valor protagónico. Durante la década de 1990 y los inicios del nuevo siglo, la figura del investigador privado ha ido desapareciendo paulatinamente de las novelas seriales negras, siendo sustituida por la de los miembros de las Fuerzas de Seguridad del Estado, que con el avance de la democracia fueron separándose de la negativa imagen que en muchos sectores sociales tenían por su brutalidad y capacidad represiva durante el franquismo. Además, con los avances tecnológicos y científicos y con las limitaciones legales, la verosimilitud que exige toda obra de género era difícil de cumplir con personajes detectivescos. Actualmente, la labor

10 «Debe ser el mejor hombre de ese mundo y un hombre suficientemente bueno en cualquier mundo, pero su vida privada no me importa demasiado» (Chandler, 1996: 79). 
de los investigadores privados acostumbra a quedar limitada a casos de adulterios, violencia callejera, desapariciones, investigaciones paralelas, espionaje industrial, etc. Por otro lado, los medios de que disponen son mucho más rudimentarios y mucho menos perfeccionados que los de los agentes policiales, que cuentan con todo tipo de recursos tecnológicos y logísticos. De ahí que el detective quede relegado a un segundo plano en la narrativa serial en beneficio de los cuerpos de seguridad estatales, tal y como demuestran los casos de Lorenzo Silva, Alicia Giménez Bartlett, Domingo Villar o el tándem formado por Empar Fernández y Pablo Bonell Goytisolo, cuyos personajes protagonistas son representantes de la Guardia Civil, la Policía Nacional y los Mossos d'Esquadra. Además de la de Cupido, ha habido otras excepciones a este panorama, como las representadas por los personajes Ángel Esquius, José García Gago, Basilio «Humphrey» Céspedes o Ricardo Blanco, detectives privados creados, respectivamente por Andreu Martín y Jaume Ribera, Antonio Lozano, Luis Gutiérrez y José Luis Correa.

\section{LA INVESTIGACIÓN: EL CONOCIMIENTO HUMANO}

Acompañado siempre de un cuaderno en el que va apuntando todos los detalles y las circunstancias de los casos que ha de resolver, Ricardo Cupido basa su trabajo en su capacidad de reflexión y observación. Para el investigador, lo principal es escuchar y presenciar las reacciones de los sospechosos ante sus preguntas. Y «su más efectiva y mejor arma habían sido siempre las palabras» (Fuentes, 2001: 90). Su modo de actuación recuerda irremediablemente al del comisario Maigret. También para el personaje de Simenon -al que, por cierto, se hace un guiño en Contrarreloj al dar su nombre a una pequeña localidad en la que transcurre parte de la acción ${ }^{11}$ - lo fundamental en una investigación era observar, comprender los modos de actuación y penetrar en las vidas de quienes formaban el círculo social y afectivo de las víctimas. Sólo de forma excepcional, en El nacimiento de Cupido y Contrarreloj, Cupido, obligado por las circunstancias de la investigación, ha de mostrar sus dotes como hombre de acción, enfrentándose violentamente a otros personajes.

El protagonista de Fuentes va a mostrar el mismo conocimiento del comportamiento humano que muestra Maigret. La solución de los casos que ha de resolver siempre aparece tras «asomarse a la intimidad de los otros» (Fuentes, 2010: 253) y, sobre todo, «cuando al fin lograba definir los retratos que iban perfilándose desde las sombras» (Fuentes, 2010: 252). De ahí que las hojas del cuaderno que utiliza como instrumento de trabajo se vayan «llenando con lo que aprendía de cada uno de los implicados, de su carácter o de sus emociones, de su apariencia física y de sus relaciones con la víctima» y de preguntas en las que importan más «los vínculos y relaciones con la víctima que las horas y lugares [de la coartada]» (Fuentes, 2010: 252). No es de extrañar, por tanto, que su compañero «el Alkalino» llegue a referirse a él como «el que sabe, el que pregunta y escucha y reflexiona y sabe», y a quienes le rodean como «lo que se sabe» (Fuentes, 2007: 73). Sin embargo, no es Cupido un detective dotado de capacidad analíticas o

11 El del personaje del escritor belga no es la única marca intertextual de la obra, que también hace un pequeño guiño a la propia obra de Eugenio Fuentes al hacer pasar a la caravana del ficticio Tour de Francia que aparece en la novela por la ciudad holandesa de Breda. 
deductivas suprahumanas que pueda llegar a la resolución de un caso con la simple observación del lugar del crimen o con un par de interrogatorios ${ }^{12}$. Si algo caracteriza su método de trabajo es la paciencia, «una larga paciencia para analizar cómo era la víctima y cómo serían sus enemigos» (Fuentes, 2010: 252), y para meditar sobre el caso a través de las relecturas de lo apuntado en el cuaderno o de la concentración suscitada por sus intensas horas de pedaleo ${ }^{13}$.

Así, a través de los interrogatorios y las rutinas profesionales de Cupido y de la capacidad del narrador omnisciente y robótico para retratar psicológicamente a los personajes, indagando en las entretelas de su pasado y su personalidad, el lector entra en contacto con una compleja galería de personajes, de forma que no es descabellado definir las novelas de Eugenio Fuentes como un compendio de biografías. De hecho, Sanz Villanueva (2007) ha llegado a afirmar que «la trama criminal, aunque valiosa, se convierte en pretexto para poner en juego una amplia nómina de caracteres» en sus obras.

El relato de esas historias personales acostumbra a tener cuatro funciones. En primer lugar, contribuye al mantenimiento de la intriga de la novela, al desgranar las relaciones de los personajes con las víctimas y las razones que podían llegar a tener para desear su muerte. En segundo, sirve para retratar, con grandes dosis de verosimilitud, los diferentes ambientes sociales y profesionales en los que el detective se inmiscuye. En tercero, está al servicio de la construcción del propio Cupido, ya que gracias a sus interacciones con los personajes de las diferentes novelas van a irse desgranando algunos aspectos de su pasado y de su personalidad. Y, por último, ayuda a enriquecer la descripción social, humana y física del espacio de Breda.

Excepto El nacimiento de Cupido, Cuerpo a Cuerpo y Contrarreloj -la acción de la primera tiene lugar en Canarias; la de la segunda en una ciudad levantina a la que el detective se desplaza para acompañar a su madre, necesitada de buen clima y baños de mar; y la de la tercera, en diversas ciudades galas, a las que se desplaza siguiendo el recorrido de una edición del Tour de Francia-, todas las novelas se desarrollan en el mítico y ficticio escenario creado por Fuentes. Especialmente interesante para la confección del espacio es $E l$ interior del bosque, que describe con minuciosidad los entornos naturales de la localidad, presentados, tras la aparición en ellos de dos cadáveres, como lugares misteriosos y solitarios en los que hasta el chasquido de una rama al romperse puede convertirse en motivo de peligro y miedo $-\mathrm{y}$ en los que todo parecía volverse «amenazador cuando lo envolvía un silencio total, no cuando se llenaba de sonidos» (Fuentes, 2005: 12)-. La novela sirve también para mostrar la dualidad que presenta la localidad, escindida entre su progresiva urba-

12 A pesar de ello, pueden establecerse analogías entre alguna de las novelas de la serie y la narrativa policiaca de finales del siglo XIX y principios del siglo XX, caracterizada, entre otras cosas, por la presencia de investigadores capaces de resolver los enigmas gracias a su portentosa inteligencia. Así puede observarse, por ejemplo, en El interior del bosque, que termina con la explicación que Cupido da al caso en una reunión a la que acuden todos los sospechosos, tal y como acostumbraba a suceder en las novelas de Agatha Christie.

13 «Su trabajo consistía en hacer estallar todo el sistema de mentiras, casi siempre complejo, tras el que se esconde y parapeta el culpable. La investigación, si se tienen fuerzas para hundirse en las miserias ajenas y para afrontar ocasionales riesgos, si se tiene resistencia para seguir insistiendo cuando todas las preguntas y respuestas parecen estériles y no se ve ninguna salida, siempre le había dado resultados, como una tierra fértil que al ser removida aúpa el cereal hacia la superficie a pesar de la sequía y de la explotación intensiva a que la han sometido. Sólo había que lanzar la palabra o la pregunta adecuada en el momento propicio, con la misma fe y seguridad con la que el campesino derrama la semilla» (Fuentes, 2001: 90). 
nización y el peso de la cultura rural, entre la modernidad del desarrollo y la pervivencia de las antiguas tradiciones. Semejante dicotomía -que recuerda a la mostrada por Francisco García Pavón en la saga policiaca protagonizada por Plinio, ambientada en Tomelloso- se observa al analizar el fresco de personajes que presenta la novela, entre los que destaca la presencia de ancianas terratenientes, agricultores apegados al trabajo y la vida del campo, artistas que traen a Breda nuevas y para algunos provocadoras costumbres, etc. Esa misma dualidad se aprecia también en Las manos del pianista, cuya trama detectivesca gira en torno al asesinato de un empresario de la construcción, lo que permite que la novela presente a la ciudad como un espacio físico cambiante por culpa del desarrollo urbanístico. Breda, tal como señala uno de los personajes de la novela, «como el resto del país, se volvió loca por construir (...): los cielos se llenaron de grúas, y al aire, de los ruidos de martillos neumáticos y golpes de tablones» (Fuentes, 2003: 112). De este modo, la novela adquiere una dimensión crítica que le lleva a denunciar cómo la «fiebre inmobiliaria» se convirtió en uno de los principales problemas de la sociedad en los últimos años, al conllevar la corrupción, el abandono escolar ante la tentación del dinero fácil, la creación de nuevas castas de ricos sin formación ni ética, la destrucción de entornos naturales, el crecimiento desordenado de las ciudades...

\section{EL CRIMEN: REALIDAD Y UNIVERSALIDAD}

Frente a esta interpretación de la novela como crónica concreta de la actualidad -presente también, de algún modo, en Contrarreloj, en la que Fuentes denuncia las prácticas ilegales de dopaje instaladas en el deporte profesional-, El interior del bosque, La sangre de los ángeles y Cuerpo a cuerpo son obras marcadas por cierta universalidad que presentan el crimen como una experiencia dramática y fruto de la debilidad que puede ser llevada a cabo por cualquier persona, por pacífica que parezca. La visión del asesinato que proyectan las novelas de Fuentes se basa en el hecho de que «los límites del mal se saltan con gran facilidad incluso por las gentes más normales y tranquilas y anodinas» (Fuentes, 2005: 194). Las implicaciones que tal interpretación tiene en sus obras no sólo residen en la ampliación del espectro de sospechosos -pues cualquiera es susceptible de cometer un acto delictivo-, sino también en la mirada compasiva y humana que se acostumbra a mostrar hacia el criminal. Lejos de intentar erigirse en portavoz de la moralidad y juzgar a los culpables, el narrador -al igual que el personaje de Cupido- intenta comprender las motivaciones que llevan a personas convencionales sin relación con los ambientes delictivos a cometer un crimen. Así se explica, por ejemplo, que el detective, tras descubrir al asesino, exprese en las páginas finales de Contrarreloj su deseo de que «tenga fortuna y encuentre la forma de redimirse sin demasiado daño» (Fuentes, 2009: 310) o que en El interior del bosque intente comprender al culpable al afirmar que «todos tenemos un punto débil sobre el cual no permitimos ninguna ofensa» (Fuentes, 2005: 330). Según Charo Alonso (2008: 136), «descreído, escéptico y pesimista como se espera de un hombre que trabaja con las miserias de otros, Cupido mantiene firme su sensibilidad agudísima, su empatía con las víctimas y su profunda compresión del mundo que le rodea». Por eso en sus obras hay una mirada compasiva y humanista hacia la víctima y hacia el criminal: ambos interesan por su condición de personas, no por su función en el relato. 
Tan sólo en El nacimiento de Cupido, la primera novela de la serie, Fuentes sitúa al personaje dentro de un espectro de personajes vinculados con el mundo del delito y la criminalidad, y en concreto con el narcotráfico y las redes de inmigración ilegal. No es la única diferencia que presenta, puesto que también se distingue del resto de entregas al prescindir de su estructura coral y homogénea -tampoco presente en Las manos del pianista, la única en la que aparece un protagonista que se eleva sobre el resto y que, de hecho, toma en diversos capítulos las riendas de la narración-. En la novela, un joven Cupido, recién salido de la cárcel y convencido de que su pasado como convicto le estigmatizará en una población pequeña como Breda, viaja hasta Canarias para iniciar una nueva vida en compañía de Siro, un antiguo amigo al que conoció haciendo el servicio militar. Cuando apenas lleva una semanas instalado en Santa Cruz de Tenerife, Siro, enrolado en las redes de narcotráfico de hachís de la isla, aparece asesinado. Dado que todas las sospechas recaen en él, Cupido se verá obligado a encontrar el culpable de la muerte de su amigo para demostrar su inocencia, convirtiéndose así en un «investigador ocasional», estereotipo del género policiaco que remite a personajes que, sin relación con el mundo de la criminalidad, son abocados por diversas circunstancias a resolver un delito. A diferencia de las siguientes novelas, en las que Cupido, ya instalado de nuevo en Breda y convertido en investigador privado, habrá de encargarse de asuntos estrictamente profesionales, en El nacimiento de Cupido el personaje ha de encontrar la solución a un caso que le afecta personalmente, tanto por la necesidad de justificar su inocencia como por el hecho de que la víctima es uno de sus mejores amigos. De ese modo, la obra hace un evidente guiño a algunas de las novelas clásicas del género negro, como El halcón maltés (Dashiell Hammett, 1929), El sueño eterno (Raymond Chandler, 1939) o Yo, el jurado (Mickey Spillane, 1946), cuyas tramas se inician con la muerte de amigos de los detectives protagonistas -respectivamente, Sam Spade, Raymond Chandler y Mike Hammer-. Tal y como ha señalado González de la Aleja (2006: 56), en estas obras se pone de manifiesto cómo en las primeras décadas del siglo XX el género policiaco pierde el carácter meramente lúdico de las narraciones de Arthur Conan Doyle o Agatha Christie, haciendo que «la solución del crimen se convierta en una búsqueda personal (...): el detective no juega a investigar, sino que se va a implicar de forma personal».

El establecimiento del vínculo emocional entre el investigador y la víctima sólo va a darse en esta primera novela. En el resto de las obras, Cupido va a limitarse a llevar a cabo una labor profesional, resolviendo simplemente los casos para los que es contratado, oscilantes entre un «repertorio de odios, inquietudes, venganzas, mínimos y rastreros delitos que aclarar, desde descubrir al autor de pequeños robos de ganado hasta encontrar a un pariente que décadas antes se marchó a Costa Rica» (Fuentes, 2005: 34). No obstante, la vinculación con la narrativa negra clásica sigue presente a través del ya mencionado carácter solitario del personaje, perfecto símbolo de su rechazo a una sociedad en la que no termina de encontrar su sitio, y en el mantenimiento de una particular ética que le lleva a no poder interpretar su actividad como la de un simple mercenario, tal y como el mismo afirma al señalar en un diálogo de Сиеrpo a cuerpo su capacidad para «elegir qué trabajos aceptar» (Fuentes 2007: 144).

La influencia de los personajes icónicos del género negro se observa en la interacción de los habitantes de Breda con Cupido. Casi todos ellos se asombran al descubrir que en una ciudad de provincias como la suya alguien pueda tener semejante trabajo y es habitual 
que muchos de ellos le confundan con un periodista cuando escuchan sus preguntas. Su sorpresa se incrementa al conocer al investigador y darse cuenta de que «no tiene aspecto de matón ni de alcohólico» (Fuentes, 2008: 75), como le dice un personaje de El interior del bosque, o de que no es «un tipo fuerte, cínico y amargado, casi telúrico en su facilidad para usar la violencia en un ambiente violento» (Fuentes, 2001: 90), tal y como el propio Cupido concibe a algunos de sus compañeros de profesión en La sangre de los ángeles.

\section{CONCLUSIÓn: REINVENTANDO EL GÉNERO POLICIACO}

Con seis novelas ya en su haber, la «serie Cupido» demuestra la habilidad de Eugenio Fuentes para reinventar y moldear a su antojo los cánones del género policiaco. El escritor ha logrado encontrar una voz propia que, al mismo tiempo que subvierte el tradicional carácter urbano de la novela negra al crear un espacio provinciano lleno de vinculaciones con el mundo rural o que sustituye el behaviorismo y el intenso ritmo por una prosa detallista de inmensa riqueza léxica y por una narración dilatada, se mantiene fiel a los elementos que configuran el andamiaje estructural del género. Partiendo de un exhaustivo conocimiento de la tradición en la que se inscribe-demostrado, como se ha venido apuntando, en los guiños, intertextos y analogías de su obra con referentes clásicos-, Fuentes consigue dotar de una nueva dimensión al género negro, haciendo que el misterio y la visión social del crimen se conviertan en meras excusas a través de las que vertebrar su preocupación humanista.

\section{BIBLIOGRAFÍA}

Alonso, Charo (2008): «Letra a letra. Eugenio Fuentes y el género negro cuerpo a cuerpo». Alcántara, 68, pp. 133-137.

Balló, Jordi y Pérez, Xavier (2005): Yo ya he estado aquí. Ficciones de la repetición, Barcelona, Anagrama.

CAsAdesús, Alejandro (2010): Sobre Wallander y Montalbano. La novela policíaca de Henning Mankell y Andrea Camilleri, Mallorca, Objeto Perdido.

CHANDLER, Raymond (1996): El simple arte de matar, León, Universidad de León.

Colmeiro, José F. (1994): La novela policiaca española. Teoría e historia crítica, Barcelona, Anthropos.

Fuentes, Eugenio (1990): Las batallas de Breda, Cáceres, Institución Cultural «El Brocense».

- (1994): El nacimiento de Cupido, Muñoz Moya y Montraveta, Sevilla.

- (2001): La sangre de los ángeles, Barcelona, Alba.

- (2003): Las manos del pianista, Barcelona, Tusquets.

- (2005): «Breda», Alcántara: revista del Seminario de Estudios Cacereños, 61-62, pp. 73-76.

- (2007): Cuerpo a cuerpo, Barcelona, Tusquets.

- (2008): El interior del bosque, Barcelona, Tusquets.

- (2009): Contrarreloj, Barcelona, Tusquets.

- (2010): «Apuntes de un detective», Sánchez Zapatero, J. y Martín Escribá, A., Realidad y ficción criminal. Dimensiones narrativas del género negro, Valladolid, Difácil, pp. 251-254.

GonZÁlez DE LA Aleja, Manuel (2006): «Novela hard-boiled: el fin de la frontera», Martín Escribá, A. y Sánchez Zapatero, J., Manuscrito criminal. Reflexiones sobre novela y cine negro, Salamanca, Cervantes, pp. 55-68. 
MADRID, Juan (1986): «El viejo placer de leer intrigas», El país (24 de diciembre de 1986), p. 25. Resina, Joan Ramón (1997): El cadáver en la cocina. La novela criminal en la cultura del desencanto, Barcelona, Antrhopos.

Sanz Villanueva, Santos (2007), «Cuerpo a cuerpo», El cultural [en línea: http://www.elcultural.es/version_papel/LETRAS/20176/Cuerpo_a_cuerpo].

SENABRE, Ricardo (2003): «Las manos del pianista», El cultural [en línea: http://www.elcultural. es/version_papel/LETRAS/6753/Las_manos_del_pianista].

Todorov, Tzvetan (1974): «Tipología de la novela policial», Fausto, 4, pp. 63-67.

Tyras, Georges (2003): Geografías de la memoria. Conversaciones con Manuel Vázquez Montalbán, Granada, Zoela.

Valles Calatrava, José R. (1991): La novela criminal española, Granada, Universidad de Granada.

VÁzQuez de PARga, Salvador (1993): La novela policiaca en España, Barcelona, Ronsel. 